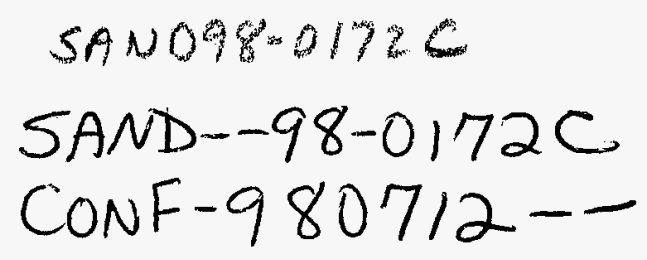

\title{
NMR STUDIES OF BOND ARRANGMENTS IN ALKALI PHOSPHATE GLASSES
}

Todd M. Alam ${ }^{\mathrm{a}}$ and Richard K. Brow

${ }^{a}$ Aging and Reliability Bulk Materials Department and

${ }^{b}$ Materials Joining Department, Sandia National Laboratories, Albuquerque, NM 87185
RECEIVED

'JAN 291998

OSTI

\section{INTRODUCTION}

Solid-state magic angle spinning (MAS) nuclear magnetic resonance (NMR) spectroscopy has become a powerful tool for the investigation of local structure and medium range order in glasses.

Previous ${ }^{31} \mathrm{P}$ MAS NMR studies have detailed the local structure for a series of phosphate glasses [1-3]. Phosphate tetrahedra within the glass network are commonly described using the $Q^{n}$ notation, where $n=$ $0,1,2,3$ and represents the number of bridging oxygens attached to the phosphate. Using ${ }^{31} \mathrm{P}$ MAS NMR different phosphate environments are readily identified and quantified. In this paper, we present a brief description of recent one dimensional (1D) ${ }^{6} \mathrm{Li}$, ${ }^{7} \mathrm{Li}$ and ${ }^{31} \mathrm{P}$ MAS experiments along with two-dimensional (2D) ${ }^{31} \mathrm{P}$ exchange NMR experiments for a series of lithium ultraphosphate glasses. From the $2 \mathrm{D}$ exchange experiments the connectivities between different $Q^{n}$ phosphate tetrahedra were directly measured, while the 1D experiments provided a measure of the P-O-P bond angle distribution and lithium coordination number as a function of $\mathrm{Li}_{2} \mathrm{O}$ concentration.

\section{EXPERIMENTAL}

Preparation and handling of the anhydrous ultraphosphate glasses has been described previously in detail [4]. The MAS NMR experiments were performed on a Bruker AMX400 using a 4mm MAS probe at a resonant frequency of $162.0,155.4$ and $58.9 \mathrm{MHz}$ for ${ }^{31} \mathrm{P},{ }^{7} \mathrm{Li}$ and ${ }^{6} \mathrm{Li}$ respectively. The $2 \mathrm{D}$ exchange experiment utilized a radio frequency dipolar recoupling sequence (RFDR) as previously described [4]. The P-O-P bond angles were obtained from a non-linear deconvolution of the ${ }^{31} \mathrm{P}$ MAS line shape assuming the relationships between ${ }^{31} \mathrm{P}$ chemical shift and the P-O-P bond angle [5].

\section{$\mathrm{Q}^{\mathrm{n}}$ CONNECTIVITIES}

The 2D RFDR NMR exchange experiments reintroduce the dipolar coupling between ${ }^{31} \mathrm{P}$ nuclei and are directly proportional to $1 / r^{3}$. Variation of the mixing time therefore provides a sensitive measure of the internuclear distance $(r)$ between phosphate tetrahedra. It has been shown that for short mixing times the $Q^{n}$ to $Q^{n^{\prime}}$ exchange rate is governed by nearest neighbor interactions and is directly related to the number of $Q^{n '}$ species attached to a $Q^{n}$ tetrahedron [4]. As an example, representative contour plots for 2D RFDR exchange experiments on the $35 \mathrm{Li}_{2} \mathrm{O} \cdot 65 \mathrm{P}_{2} \mathrm{O}_{5}$ glass at zero mixing time and $2.56 \mathrm{~ms}$ mixing are shown in Fig. $1 \mathrm{a}$ and $1 \mathrm{~b}$, respectively. The off diagonal signal intensity in the $2.56 \mathrm{~ms}$ contour plot (Fig. 1b) clearly shows magnetization exchange due to nearest neighbor dipolar interactions. Simple quantitative information can be obtained by taking a 1D slice through the isotropic chemical shifts corresponding to different $Q^{n}$ species. Figures $1 c$ and $1 d$ show the $1 D$ slices taken through the $Q^{2}$ chemical shift ( $\delta=-30.8 \mathrm{ppm}$ ) at $0 \mathrm{~ms}$ and $2.56 \mathrm{~ms}$ mixing times. At zero mixing time (Fig. $1 \mathrm{c}$ ) only a narrow Lorentzian line is observed representing non-exchange magnetization. At $2.56 \mathrm{~ms}$ (Fig. $1 \mathrm{~d}$ ) the $\mathrm{Q}^{2}$ cross section shows three resonances: (1) a narrow Lorentzian for the non-exchanging $\mathrm{Q}^{2}$ magnetization, $Q^{2}(0),(2)$ a broad resonance at $\delta=-30.8 \mathrm{ppm}$ resulting from $\mathrm{Q}^{2} \rightarrow \mathrm{Q}^{2}$ exchange and (3) another broad resonance at $\delta=-44.1 \mathrm{ppm}$ resulting from $Q^{2} \rightarrow Q^{3}$ exchange. Similarly, the slice through the $Q^{3}$ chemical shift at $\delta=-44.1 \mathrm{ppm}$ (Figs. $1 \mathrm{e}$ and $1 \mathrm{f}$ ) can also be deconvoluted into three overlapping resonances as seen in the insets. 


\section{DISCLAIMER}

This report was prepared as an account of work sponsored by an agency of the United States Government. Neither the United States Government nor any agency thereof, nor any of their employees, makes any warranty, express or implied, or assumes any legal liability or responsibility for the accuracy, completeness, or usefulness of any information, apparatus, product, or process disclosed, or represents that its use would not infringe privately owned rights. Reference herein to any specilic commercial product, process, or service by trade name, trademark, manufacturer, or otherwise does not necessarily constitute or imply its endorsement, recommendation, or favoring by the United States Government or any agency thereof. The views and opinions of authors expressed herein do not necessarily state or reflect those of the United States Government or any agency thereof. 

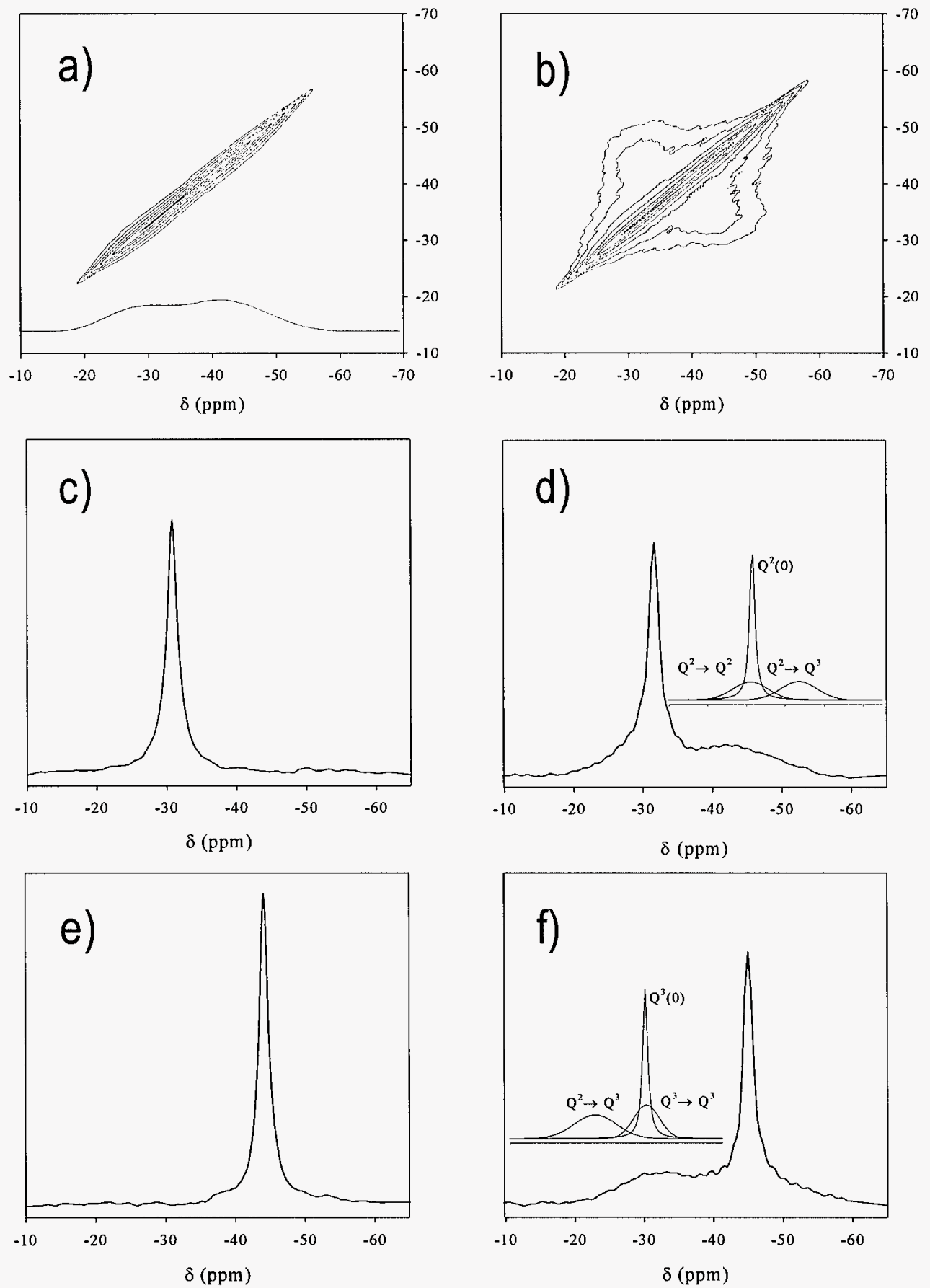

Figure 1. 2D RFDR ${ }^{31} \mathrm{P}$ MAS NMR exchange contour plots for the $35 \mathrm{Li}_{2} \mathrm{O} \cdot 65 \mathrm{P}_{2} \mathrm{O}_{5}$ glass at a) 0 ms and b) $2.56 \mathrm{~ms}$ mixing times. Cross sections were taken through the isotropic resonance corresponding to the different $Q^{n}$ species for different mixing times: c) $\left.Q^{2} \delta=-30.8 \mathrm{ppm}, \tau_{\text {mix }}=0.0 \mathrm{~ms}, \mathrm{e}\right) \mathrm{Q}^{3}, \delta=-44.1 \mathrm{ppm}$, $\left.\tau_{\text {mix }}=0.0 \mathrm{~ms} \mathrm{d)} \mathrm{Q}^{2} \tau_{\text {mix }}=2.56 \mathrm{~ms}, \mathrm{f}\right) \mathrm{Q}^{3} \tau_{\text {mix }}=2.56 \mathrm{~ms}$. Each mixing time is plotted on the same relative intensity scale. For this glass composition the exchange is almost equally distributed between different $Q^{2}-Q^{3}, Q^{3}-Q^{3}$ and $Q^{2}-Q^{2}$ connectivities (inset). 
The relative areas of these exchange cross peaks can be compared to the connectivity distributions predicted for different glass structural models. For example, the relative exchange functions observed experimentally compare well to those predicted for a glass that has undergone random depolymerization as shown in Fig. 2 [4]. Contrast this to the exchange functions that would result from a glass containing highly segregated $Q^{3}$ and $Q^{2}$ domains (microdomains). In the case of microdomains the $Q^{3} \rightarrow Q^{3}$ and $Q^{2} \rightarrow Q^{2}$ transfer functions would be predicted to be near unity for large regions of $\mathrm{Li}_{2} \mathrm{O}$ concentrations ( all nearest neighbors of same $Q^{n}$ type). From inspection of Fig. 2 , it is clear that this was not observed experimentally, precluding microdomain formation in the lithium ultraphosphate glasses presented here.
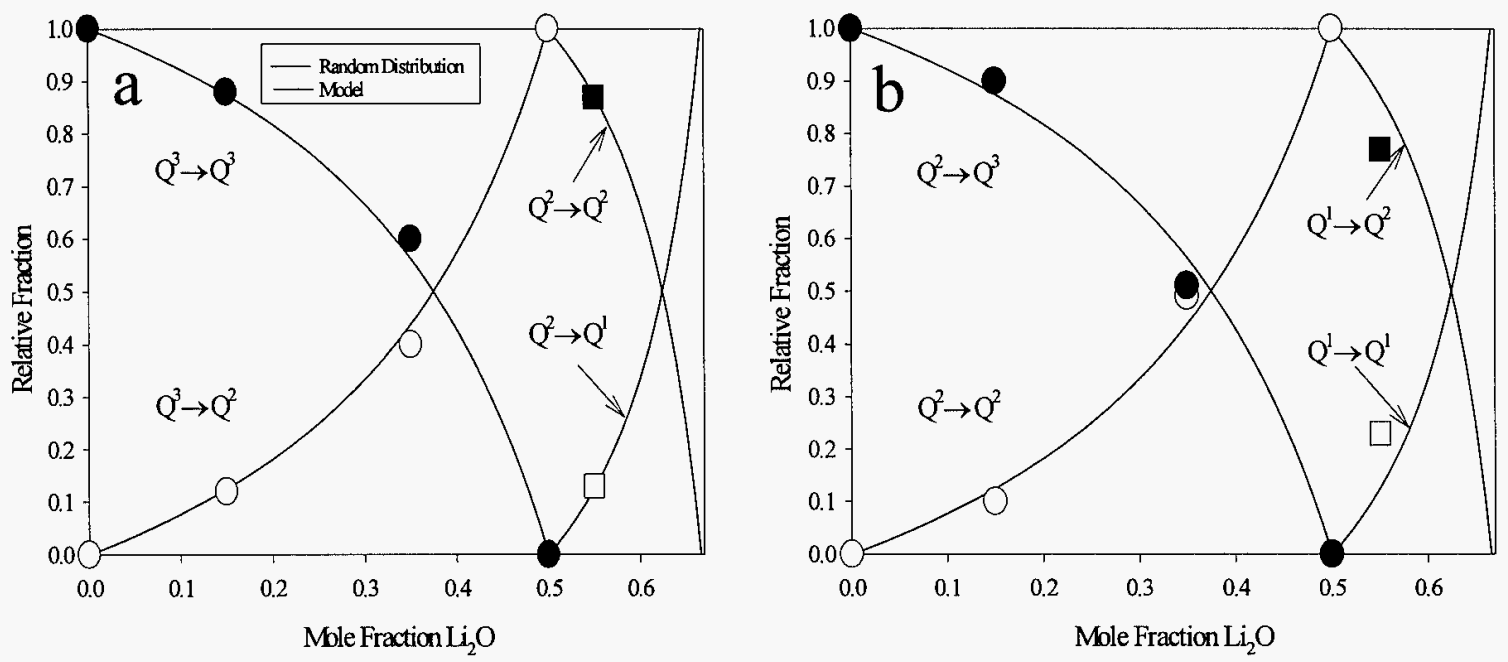

Figure 2. Theoretical transfer functions $\left(Q^{n} \rightarrow Q^{n^{\prime}}\right.$ ) assuming a randomly depolymerized model in a binary phosphate glass versus experimental $(\bullet, O)$ NMR transfer functions obtained from 2D RFDR ${ }^{31} P$ MAS NMR exchange experiments for $\mathrm{xLi}_{2} \mathrm{O} \bullet(1-\mathrm{x}) \mathrm{P}_{2} \mathrm{O}_{5}$ glasses.

Table 1: ${ }^{31} \mathrm{P}$ NMR Chemical Shifts, Line Widths, Homogenous Line Widths $(\Delta v)$ and Bond Angle Distribution Widths $(\Delta \theta)$ For Various $\mathrm{xLi}_{2} \mathrm{O} \cdot(1-\mathrm{x}) \mathrm{P}_{2} \mathrm{O}_{5}$ Glasses.

\begin{tabular}{ccccc}
\hline Glass $/$ Resonance & $\delta_{\text {iso }}(\mathrm{ppm})$ & $\mathrm{FWHM}(\mathrm{Hz})$ & $\Delta \mathrm{v}(\mathrm{Hz})$ & $\Delta \theta(\mathrm{deg})$ \\
\hline $\mathrm{P}_{2} \mathrm{O}_{5}$ & -52.9 & 2137 & 46 & 24 \\
$\mathrm{Q}^{3}$ & & & & \\
$15 \mathrm{Li}_{2} \mathrm{O} \cdot 85 \mathrm{P}_{2} \mathrm{O}_{5}$ & -51.8 & 2380 & 34 & 28 \\
$\mathrm{Q}^{3}$ & -34.5 & 1380 & 30 & 25 \\
$\mathrm{Q}^{2}$ & -44.1 & & & \\
$35 \mathrm{Li}_{2} \mathrm{O} \cdot 65 \mathrm{P}_{2} \mathrm{O}_{5}$ & -30.8 & 2530 & 20 & 23 \\
$\mathrm{Q}^{3}$ & & 1850 & 35 & 28 \\
$\mathrm{Q}^{2}$ & -40.0 & 2274 & 20 & 20 \\
$43 \mathrm{Li}_{2} \mathrm{O} \cdot 57 \mathrm{P}_{2} \mathrm{O}_{5}$ & -24.7 & 1703 & 45 & 26 \\
$\mathrm{Q}^{3}$ & -23.56 & 1186 & 64 & 15 \\
$\mathrm{Q}^{2}$ & & & & \\
$50 \mathrm{Li}_{2} \mathrm{O} \cdot 50 \mathrm{P}_{2} \mathrm{O}_{5}$ & -23.5 & 1580 & 46 & 19 \\
$\mathrm{Q}^{2}$ & -5.6 & 1030 & 38 & 20 \\
$55 \mathrm{Li}_{2} \mathrm{O} \cdot 45 \mathrm{P}_{2} \mathrm{O}_{5}$ & & & & \\
$\mathrm{Q}^{2}$ & & &
\end{tabular}




\section{P-O-P BOND ANGLE DISTRIBUTIONS}

In addition to the measurement of tetrahedra connectivities, additional structural parameters of the glass can be obtained from ${ }^{31} \mathrm{P}$ MAS NMR. It has been argued that the wide line widths observed in the ${ }^{31} \mathrm{P}$ MAS NMR experiments (Table 1) do not result from homogenous broadening, but instead arise from inhomogenous broadening due to variations in the P-O-P bond angle and P-O bond lengths that produce small changes in the chemical shift. The 2D experiments presented in Fig. 1 confirm this argument, clearly showing that for a given frequency the homogenous line width is quite narrow. Additional rotor-syncronized two pulse Hahn echo (TPHE) experiments have determined the homogenous line width vary between 0.1 to $0.3 \mathrm{ppm}$ for the entire $\mathrm{Li}_{2} \mathrm{O}$ range investigated and are much narrower than the observed 1D line widths. Using the semi-empirical relationships between ${ }^{31} \mathrm{P}$ chemical shift and changes in the P-O-P bond angle [5] the P-O-P bond angle distributions were obtained, and are shown in Fig. 3.
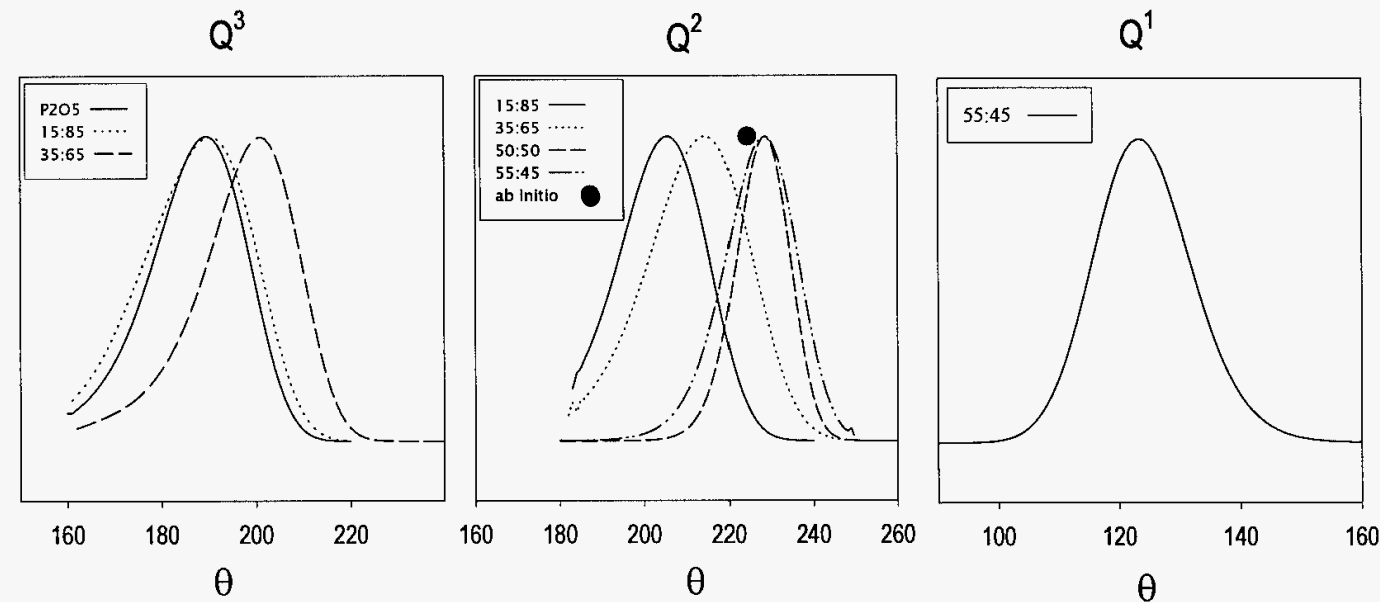

Figure 3. The $\mathrm{P}-\mathrm{O}-\mathrm{P}$ angle $(\theta)$ distributions for the $\mathrm{Li}_{2} \mathrm{O} \cdot \mathrm{P}_{2} \mathrm{O}_{5}$ glasses. The mean angle predicted from $a b$ initio calculations (O) for the Li metaphosphate (50:50) [6] is shown for comparison.

The agreement between the mean P-O-P bond angle $(\theta)$ and those predicted from ab initio calculations for the lithium metaphosphate $(50: 50)$ [6] are good, while the mean angle for the $Q^{3}$ tetrahedra in $\mathrm{P}_{2} \mathrm{O}_{5}$ differs significantly than that reported for the $\mathrm{X}$-ray structure of crystalline $\mathrm{P}_{2} \mathrm{O}_{5}$. This discrepency suggest that the $Q^{3}$ chemical shift relation provided by Sternberg et al. [5] may need additional refinement. The experimental P-O-P bond angle distributions in Fig. 3 provide a critical benchmark for future computer modeling. The full width at half maximum of these bond angle distributions $(\Delta \theta)$ as a function of mole fraction $\mathrm{Li}_{2} \mathrm{O}_{5}$ can also be used as a matrix of changes in glass structure.

These variations in $\Delta \theta$ together with changes in the glass transition temperature $\left(T_{g}\right)$ are shown in Fig. 4. At low $\mathrm{Li}_{2} \mathrm{O}$ content there is an initial disruption of the 3D phosphate network as seen by a small increase in $\Delta \theta$. As the glass approaches the metaphosphate concentration there is a reduction in $\Delta \theta$ for both $Q^{3}$ and $Q^{2}$, suggesting an increase in the structural order with increasing $\mathrm{Li}_{2} \mathrm{O}$ concentration. The phenomena responsible for this increased ordering is still under investigation.

Figure 4. P-O-P bond angle distribution $(\Delta \theta)$ with $\mathrm{Li}_{2} \mathrm{O}$ content in the lithium phosphate glasses. Lines are drawn as guides for the eye.

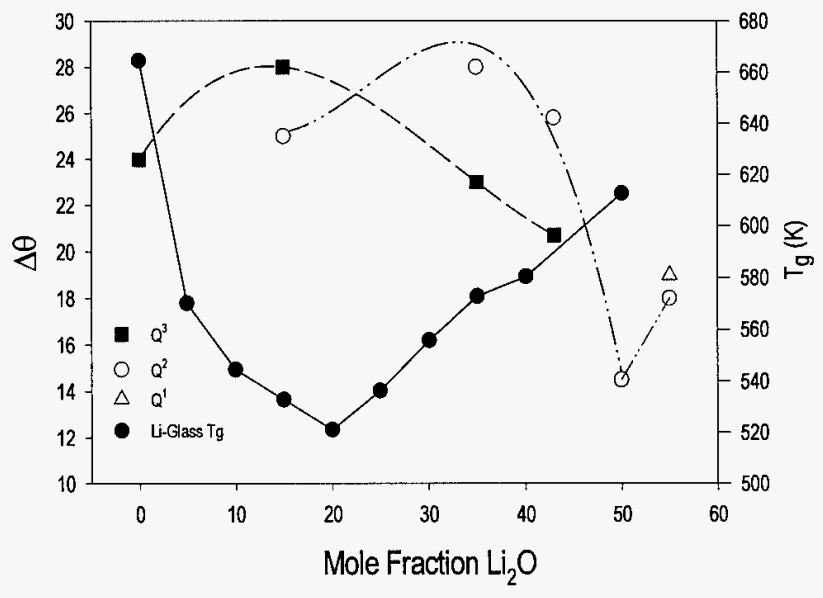




\section{LITHIUM COORDINATION}

The local structure for the alkali modifiers can be investigated using NMR for a variety of nucleus. Determination of the chemical shift for the modifying cation in glasses has been shown to be strongly influenced by the number of oxygens in the first coordination sphere. These chemical shift variations have been observed for ${ }^{6} \mathrm{Li},{ }^{7} \mathrm{Li},{ }^{23} \mathrm{Na},{ }^{25} \mathrm{Mg}$ and ${ }^{27} \mathrm{AI} \mathrm{NMR}[2,3,7]$. By combining ${ }^{6} \mathrm{Li}$ and ${ }^{7} \mathrm{Li} \mathrm{MAS}$ NMR investigations for the ultraphosphate glasses discussed here, changes in the local coordination of the lithium cation were addressed.

Representative solid state MAS NMR spectra for lithium ultraphosphate glasses are shown in for ${ }^{7} \mathrm{Li}$ (Fig. 5a) and for ${ }^{6} \mathrm{Li}$ (Fig. 5b). Both ${ }^{7} \mathrm{Li}(\mathrm{I}=3 / 2)$ and ${ }^{6} \mathrm{Li}(\mathrm{I}=1)$ are quadrupolar nuclei requiring determination of the quadrupolar shift in order to obtain true chemical shift information. For the ultraphosphate glasses the quadrupolar interaction is small enough such that second order quadrupolar line shape perturbations were not observed. Inspection of Fig. 5a shows a strong central resonance (resulting from the $\pm 1 / 2 \leftrightarrow \mp 1 / 2$ transition) with a sideband manifold due to the $\pm 3 / 2 \leftrightarrow \pm 1 / 2$ transitions. The first order quadrupolar interaction has no effect on the central transition while the second order quadrupolar shift for the $\mathrm{m}-1 \leftrightarrow \mathrm{m}$ transition in ppm is defined by

$$
\delta_{i s o}^{(2 Q)}=-\frac{3}{40} \frac{C_{Q}^{2}}{v_{L}^{2}} \frac{(I(I+1)-3-9 m(m-1))}{I^{2}(2 I-1)^{2}}\left(1+\frac{\eta_{Q}^{2}}{3}\right) \times 10^{6}
$$

where $C_{Q}$ is the quadrupolar coupling constant, $\eta_{Q}$ is the quadrupolar asymmetry parameter and $v_{L}$ is the Larmor frequency. The observed shift in the MAS spectra is then given by the sum of the chemical shift and this second order isotropic shift

$$
\delta^{o b s}=\delta^{C S}+\delta_{i s o}^{(2 Q)}
$$

For ${ }^{6} \mathrm{Li}$ (Fig. 5b) only a single resonance was observed resulting from the $\pm 1 \leftrightarrow 0$ transition, again with the second order quadrupolar isotropic shift given by Eqn. 1. Because the quadrupolar moment of ${ }^{6} \mathrm{Li}$ is $\sim 1 / 50$ that of ${ }^{7} \mathrm{Li}[7]$ the magnitude of the second quadrupolar shift to the observed shift is negligible. This results in the observed ${ }^{6} \mathrm{Li}$ shift observed in the MAS spectra (Fig. 5b) being a close approximation for the true chemical shift. The difference between the shifts observed in the ${ }^{7} \mathrm{Li}$ and ${ }^{6} \mathrm{Li}$ Mas spectra provide a measure of the quadrupolar coupling constant $\left(C_{0}\right)$ using Eqns. 1 and 2. For the lithium ultraphosphate glasses the shift difference at 9.4 Tesla were very small $(<0.1 \mathrm{ppm}$ which is approximately the resolution limit due to line width) providing an upper limit of approximately $0.5 \mathrm{MHz}$ for the quadrupolar coupling constant. $A$ more accurate estimate of $\mathrm{C}_{\mathrm{Q}}$ as a function of $\mathrm{Li}$ modifier concentration could be obtained from the inverse proportionality of the quadrupolar shift to $v_{L}^{2}$. Determination of the ${ }^{7} \mathrm{Li}$ shifts at different field strengths are presently being pursued.

Figure 5. Representative a) ${ }^{7} \mathrm{Li}$ and b) ${ }^{6} \mathrm{Li}$ MAS NMR for $x \mathrm{Li}_{2} \mathrm{O} \bullet(1-$ x) $\mathrm{P}_{2} \mathrm{O}_{5}$ glasses. The ${ }^{7} \mathrm{Li}$ spectra shows a strong central resonance for the $\pm 1 / 2 \leftrightarrow \mp 1 / 2$ transition and a spinning sideband manifold resulting from the $\pm 3 / 2 \leftrightarrow \pm 1 / 2$ transitions. The ${ }^{6} \mathrm{Li}$ spectra shows only a single resonance, with a negligible second order quadrupolar shift, providing a good approximation of the true chemical shift. The variation of the ${ }^{6} \mathrm{Li}$ chemical shift (inset) versus $\mathrm{Li}_{2} \mathrm{O}$ concetrations reveals a continuous decrease in the $\mathrm{Li}$ coordination number.
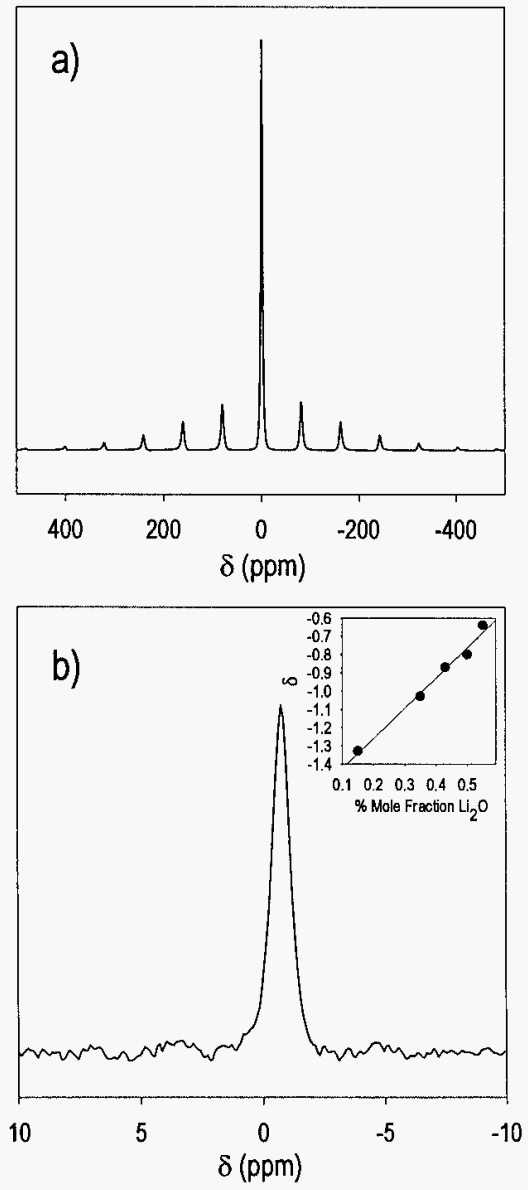
Fig. $5 \mathrm{~b}$ (inset) shows the ${ }^{6} \mathrm{Li}$ chemical shift variation as a function mole percent $\mathrm{Li}_{2} \mathrm{O}$ added to the glass. A linear increase in the chemical shift with increasing mole fraction is observed. Additional glass with compositions in the critical region between 20 and 30 mole percent $\mathrm{Li}_{2} \mathrm{O}$ are being prepared to better define this trend near the minimum $\mathrm{T}_{\mathrm{g}}$ region. In silicate glasses increases in the chemical shift have been correlated to a decrease in the coordination number of the lithium.[7] Similar changes in the chemical shift have been reported for ${ }^{27} \mathrm{Al},{ }^{23} \mathrm{Na}$ and ${ }^{25} \mathrm{Mg}$. For the lithium ultraphosphate glasses the chemical shift variations correspond to the $\mathrm{Li}$ coordination changing from $\mathrm{LiO}_{6}$ in the $15 \mathrm{Li}_{2} \mathrm{O} \cdot 85 \mathrm{P}_{2} \mathrm{O}_{5}$ glass towards increasing amounts of $\mathrm{LiO}_{5}$ and $\mathrm{LiO}_{4}$ species at higher $\mathrm{Li}_{2} \mathrm{O}$ concentrations. This trend in ${ }^{6} \mathrm{Li}$ chemical shift with changing $\mathrm{Li}_{2} \mathrm{O}$ concentration does not suggest the formation of microdomains, and supports the random depolymerization structural model discussed above. It is true that he correlation reported for lithium silicate glasses [7] may not be directly applicable to the lithium phosphate glasses discussed here, necessitating future investigation of lithium coordination in crystalline phosphate systems.

\section{CONCLUSIONS}

The results from several different types of NMR experiments have been present, and provide examples of the types of structural information that can be obtained using NMR techniques. The ability to probe medium range order using NMR exchange experiments was also demonstrated, and demonstrates the applicability of multi-dimensional NMR techniques to probe structure in amorphous glasses and complex ceramics.

\section{References}

[1]. S.W. Martin,"Review of the Structures of Phosphate Glasses", Eur. J. Solid State Inorg. Chem. 28 163-205 (1991).

[2]. H. Eckert,"Structural Characterization of Noncrystalline Solids and Glasses Using Solid State NMR", Prog. Nucl. Magn. Reson. Spectrosc. 24 159-293 (1992).

[3]. R.J. Kirkpatrick and R.K. Brow,"Nuclear Magnetic Resonance Investigation of the Structures of Phosphate-Containing Glasses: A Review", Solid State Nucl. Magn. Reson. 5 9-21 (1995).

[4]. T.M. Alam and R.K. Brow,"Local structure and Connectivity in Lithium Phosphate Glasses: a Solid-

State ${ }^{31}$ P MAS NMR and 2D Exchange Investigation", J. Non-Cryst. Solids In Press (1998).

[5]. U. Sternberg, F. Pietrowski and W. Priess,"The Influence of Structure and Coordination on the ${ }^{31} \mathrm{P}$ Chemical Shift in Phosphates", Z. Physik. Chemie Meue Folge, Bd. 168 115-128 (1990).

[6]. T. Uchino and Y. Ogata,"Ab Initio Molecular Orbital Calculations on the Electronic Structure of Phosphate Glasses. Binary Alkali Metaphosphate Glasses", J. Non-Cryst. Solids 191 56-70 (1995).

[7]. Z. Xu and J.F. Stebbins," 6 Li Nuclear Magnetic Resonance Chemical Shifts, Coordination Number and Relaxation in Crystalline and Glassy Silicates", Solid State Nuclear Magn. Res. 5 103-112 (1995).

\section{Acknowledgments}

The authors are indebted to Dr. J.J. Hudgens for providing the ultraphosphate glasses. Sandia is a multiprogram laboratory operated by Sandia Corporation, a Lockheed Martin Company, for the United States Department of Energy under Contract DE-AC04-AL85000. 

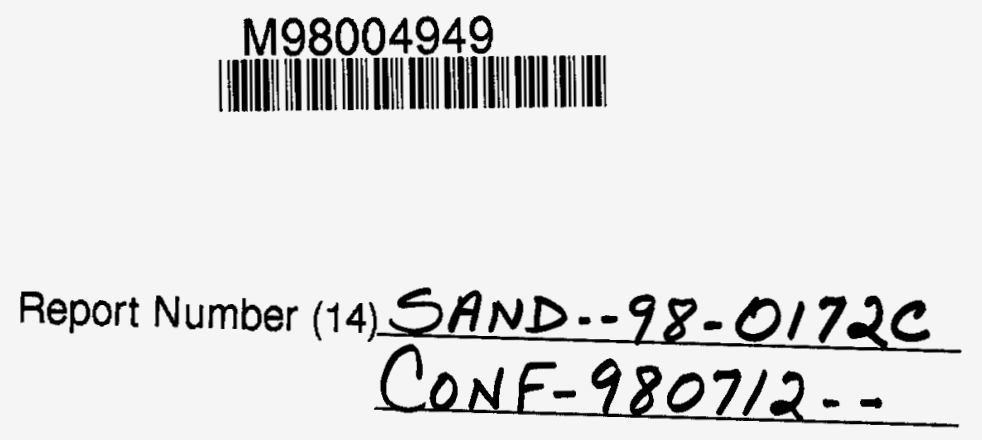

Dubl. Date (11) 199801

Sponsor Code (18) DOE/ER , XF

JC Category (19) UC-400, DOE/ER

19980619074 